\title{
Effect of Internal Marketing on Organizational Silence Mediated by Organizational Culture: the Case of Ferdowsi University Employees
}

\author{
Raoufeh Sadat Ja'farian, Vajiheh Hoshyar, Elham Yazdanmehr
}

\begin{abstract}
The present research explored the effect of internal marketing on organizational silence mediated by organizational culture among the employees of Ferdowsi University of Mashhad. The present applied research used descriptive data to conduct a survey. The research population was the employees of Ferdowsi University of Mashhad, 968 in total. The data were collected in 2018. Using Cochran's formula, the required sample size was estimated at 275 , and the sampling method was convenient. For data collection, three questionnaires were used: the internal marketing questionnaire (Pournabi, 2015), organizational silence (Mirkamali, Poorkarimi, \& Karami, 2017) and organizational culture (Denison, 2000). For descriptive statistics, frequencies, percentages and standard deviations were used. For inferential statistics, first the normality of data was checked through Kolmogorov-Smirnov test. The skewness and kurtosis were also checked. To test the conceptual model, to analyze observations and to explore the concurrent effects of variables within the model, structural equation modelling (SEM) was used. The required analyses were run via SPSS22 and SmartPLS at the significance level of .05. To test convergent and discriminant validity, average variance extracted (AVE) was used and to test the reliability of questionnaires, Cronbach's alpha test of internal consistency was run (internal marketing $=97 \%$, organizational silence $=94 \%$ and organizational culture $=95 \%$ ) along with the PLS approach. The research findings revealed a statistically significant negative correlation between internal marketing and organizational silence. A statistically significant positive correlation was estimated between internal marketing and organizational culture. A statistically significant negative correlation was found between organizational culture and organizational silence. Organizational culture mediated the correlation between internal marketing and organizational silence.
\end{abstract}

Key words: employees, Ferdowsi University of Mashhad, internal marketing, organizational culture, organizational silence.

\section{INTRODUCTION}

In the ever-changing world today, many organizations seek to find a way to gain a privilege in competition to attract and satisfy customers. Organizations expect their employees to be responsible and innovative and share opinions about the existing internal issues of their workplace. However, employees complain that their organization of affiliation does not welcome open communications and sharing of knowledge.

Revised Manuscript Received on October 10, 2019.

* Correspondence Author

Raoufeh Sadat Ja'farian, M.A., Management Studies, Attar Institute of Higher Education), Email address: r.jafarian1993@gmail.com.

Vajiheh Hoshyar, Assistant Professor, Attar Institute of Higher Education), Email address: v.hoshyar@attar.ac.ir,

Elham Yazdanmehr*, Assistant Professor, Attar Institute of Higher Education), Email address: yazdanmehr@attar.ac.ir

(c) The Authors. Published by Blue Eyes Intelligence Engineering and Sciences Publication (BEIESP). This is an open access article under the CC BY-NC-ND license (http://creativecommons.org/licenses/by-nc-nd/4.0/)
Thus, they avoid sharing ideas and thoughts quite on purpose. This would put the organization at the risk organizational silence. If so, managers should be expecting a serious threat which should be prevented at the right time. Internal marketing can be a solution to this problem and proved effective in the related literature. Internal marketing is a process which affects organizational silence significantly (Dalvi \& Sefiddashti, 2013). Moreover, development of internal marketing can create a culture in the organization that acts as the best and most effective way to reduce employees' silence and increase their satisfaction.

Organizational culture, as a key factor, affects organizational behavior and all that of all members (Park \& Kim, 2009). Culture can help an organization progress or can stop it somewhere in the mid-way. This potential is strengthened by the effect of organizational culture on employees' behavior (Doostmohammadi, 2007). Employees' silence is a type of organizational behavior that can stop organizational progress. As the body of related literature shows that organizational culture affects organizational silence (Khamesihamaneh, 2013), employees should be made satisfied and their satisfaction, as internal customers, significantly affects the loyalty of external customers. Other investigations showed that internal marketing was significantly and positively correlated with organizational culture (Fathollahi, Kord-Jamshidi, Darabi, \& Shirkhani, 2016). Therefore, organizations need to focus their attempts on the development and reinforcement of an organizational culture that takes into account internal customer (employee) satisfaction as well as external customers. A variable that can be manipulated to increase the correlation of internal marketing and employees' satisfaction is organizational culture. Employees' higher satisfaction would break their silence (Taliban, HajiMohammadi, \& Taliban, 2015).

The present research aimed to cast a look inside organizations which dramatically affects organizational development and promotion generally and Ferdowsi University of Mashhad particularly. As countries worldwide move towards globalization, they need to attend more to internal marketing to overcome the existing challenges. The findings can help the target university implement marketing policies more than ever before with the aim of eliminating employees' organizational silence.

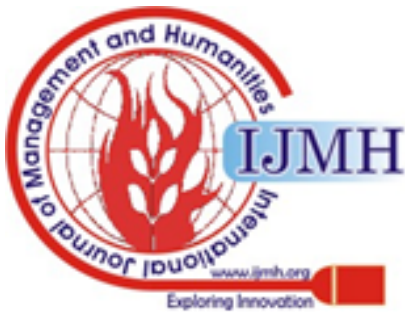




\section{A. Theoretical background and review of the related literature:}

\section{Internal marketing}

Berry and Gronroos were pioneering figures in introducing internal marketing as a way of avoiding the issue of organizational silence. According to Kotler, organizations need to engage in internal marketing as well as external marketing. He defined the former as the process of successfully employing, training and motivating employees, and prioritized it to external marketing (Kotler, 2008). The clearest conceptualization of internal marketing was proposed by Piercy and Morgan (1991) and extended by Rafiq and Ahmed (1993), who defined internal marketing as planned efforts to make changes and extension, motivate employees, homogenize tasks and integrate employees (Rafiq \& Ahmed, 1993). Gronroos maintained that internal marketing aims to homogenize the dynamicity of different internal activities (of organization) and motivate employees to serve customers at their best and adopt a customeroriented approach in practice (Gronross, 2000). Bansal et al. (in their model adopted in the present research) defined multiple aspects of internal marketing among employees as job security, extensive training, generous rewards, shared information, employee empowerment and reduced status distinction (Bansal \& Morris, 2001). As described by Ballantyne, internal marketing helps update organizational knowledge (Ballantyne, 2003). In the present research, internal marketing is an independent variable the main constituent elements are:

Job security: Reduced productivity or profit-making can lead to employees' transfer, retraining and job turnover. One way to prevent employee attrition is the possibility of using them in other sections. Investigations have shown that employees' more job security is accompanied by more satisfaction, loyalty and trust in management.

- Various extensive training: In a developed global economy, emergence and development of knowledge is a key factor to gain a competitive privilege at a global scale. Research-based evidence has shown that investment in training can have tangible consequences that include better attitudes and more skills in promoting the quality of services and increasing employee satisfaction and loyalty (Gounaris, 2008).

- Generous rewards: There is evidence that employees in companies that offer higher income and benefits are more satisfied with and committed to the organization of affiliation (Unesifar, Mohaqar, \& Unesifar, 2013).

- Sharing information: For communicative purposes and sharing information, organizations need to use different methods. The aim is to facilitate decisionmaking, promote the level of capabilities and create a proper feedback mechanism (Baqeri, Shahir-Tofiq, Zarifi, \& Deldar, 2017).

- Employee empowerment: This is of a great significance as organizations are attacked both from inside and outside. The latter is caused by intense competition, rapid changes and new demand for quality services and limited sources that require a quick response. The former is induced by employees who feel they are treated unfair and, thus, get frustrated. Still faced with the high expectations of organization, they need to take serious measures to empower the employees (Unesifar et al., 2013).

Reduced status distinction among employees: This can help employees express their opinions freely, and can thus increase creativity, integrity, trust and job satisfaction. To reduce status distinction, they can either reduce the distinction of income and salaries within an organization or create organizational symbols for communicative purposes to develop integrity culture, trust and organizational fairness (Unesifar et al., 2013).

\section{Organizational silence}

As maintained by Morrison and Milliken, when the majority of employees decide to keep silent about organizational issues, silence prevails as a collective phenomenon, often referred to as organizational silence (Morrison \& Milliken, 2000). Pinder and Harlos conceptualize employee silence as a cooperative act to refrain from telling the truth about certain organizational conditions to particular staff who are in the position to make changes (Pinder \& Harlos, 2001). Organizational silence was defined as deliberate avoidance to share work-related opinions, information and comments (Dyne, 2003). Perlow and Williams (2003) maintained that the complicated nature of organizational silence emerges when the affiliated members refrain from discussing differences or prevent discussions that may cause trouble. Organizational silence refers to a collective event or some minor response to key issues that face an organization (Henriksen \& Dayton, 2006). Silence was more recently defined as employees' retention of concerns about key issues related to their job or the organization they work for (Brinsfield, 2013). Five types of organizational silence explored in the present research were:

Acquiescent silence: Employees keep silent as they believe supervisors and senior management do not welcome their opinions and find them irrelevant. Those adopting this kind of silence give in to current conditions and are reluctant to make any attempts or discuss issues to change the status quo. Among the behavioral traits of those preferring this silence are less cooperation, neglect, carelessness, ignorance and recession (Pinder \& Harlos, 2001).

Defensive silence: This type of silence is avoidance of expressing ideas due to fear and for the sake of selfmaintenance. This silence is indicative of intentional lack of cooperation and thus staying out of decision-making, rooted in the fear of consequences of discussing or sharing information. Defensive silence is a deliberate and nonpassive behavior shown to protect oneself against external threats (Karami, Mirkamali, \& Pourkarimi, 2016).

Prosocial silence: This silence involves avoidance of expressing ideas, information and work-related opinions so as to benefit others or the organization of affiliation motivated by prosocial considerations. This kind of silence is deliberate and non-passive and is explained by ethical or communicative issues only conditionally. 
Moreover, researchers believe there is a strong correlation between prosocial silence and chivalry usually accompanied by the avoidance of complaint and tolerance of difficulties at work with no complaint (Dyne et al., 2003).

Opportunistic silence: Occasionally, employees refrain from disclosing information for self-interest. In this definition, reference is made to opportunism described by Williamson as "opportunism with guile". Employees' refraining from information disclosure, if the aim is not to lose power/status or if they aim to escape work pressures can be as effective. Overall, opportunistic silence is defined as the act of avoiding expression of ideas, information or comments about work for self-interest and acceptance of damage to others (Knoll \& van Dick, 2013).

Embarrassed silence: This silence implies hesitation in speech and action motivated by lacking self-confidence. This type of silence is comprised of such features as low self-confidence, self-doubt, doubt in one's status or desires. This type of silence might overlap in cases with defensive silence, as it similarly occurs so as to prevent adverse effects. Yet, the nature of adverse effects lies in one's internal world (Brinsfield, 2013).

\section{Organizational culture}

Organizational culture has been defined in multiple ways. Several researchers including Edgar Schein perceive culture as a pattern of fundamental assumptions that group members learn in the face of challenges to adapt themselves with external environment and try internal integration (Baker, 2002). Denison (whose model is the target model in the present research) maintained that organizational culture refers to underlying values, beliefs and principles that act as the basis of organization management systems, functions and behaviors (Denison, 2000). Overall, what is common to all these definitions of organizational culture is a set of beliefs and values shared by all members at the core. Thus, organizational culture can be defined as a system of common beliefs and values that emerge in an organization and guides all members' behavior (Monavarian \& Bakhtaei, 2006). According to Denison, organizational culture is characterized by four key features: involvement in work (involvement), stability and integration (consistency), adaptability and mission. These dimensions are measured on fourteen indices, which together, make Denison's model of organizational culture. These are introduced below:

Involvement: Effective organizations empower their employees and center their activities on team work. Thus, they develop the capabilities of their human resource at all levels. They encourage employee involvement in different activities within the organization, which would create a sense of commitment and ownership and would add to independence capabilities. Sense of ownership can cause more commitment to the organization of affiliation. Truly committed employees see themselves as part of the organization body and feel part of the decision-making process. These decisions can tremendously affect their work and their work is hand in hand with organizational goals and objectives (Danayifard et al., 2011). The underlying indices of involvement are empowerment, team orientation and capability development (Vashghani Farhani, 2009).

Consistency: Consistency is comprised of values and systems that are at the core of a rich culture. Effective organizations are consistent and integrated. In such organizations, the behavior of members is rooted in a set of core values. Leaders and followers are skilled in how to reach agreement and this skill is necessary for agreeing on complicated issues especially when they are of opposite views. Consistency would enable one to show the right reaction in a predictable manner to unpredictable cases. The indices of consistency are: core values, agreement, coordination and integration (Danayifard \& Panahi, 2011).

Adaptability: This feature deals with attention to the requirements of workplace in activities. Flexible organizations possess a system of norms and beliefs that increases the capabilities of perceiving, interpreting and applying contextual cues to create internal changes to organizations. This system would raise the odds of survival, growth and development of an organization. This feature has got several indices including creating change, customer focus and organization learning (Danayifard et al., 2011).

Mission: This feature includes defining and specifying the long-term orientations of organization. A clear understanding of organizational mission enables employees to form a clear vision of desirable prospects and form the current organizational behavior. Organizations that lack the required knowledge of their current status often go astray. Successful organizations are well aware of their goals and orientations. They prespecify organizational and strategic goals and define organizational vision. The constituent indices of mission are: strategic direction and intent, goals and objectives and vision (Denison, 2000).

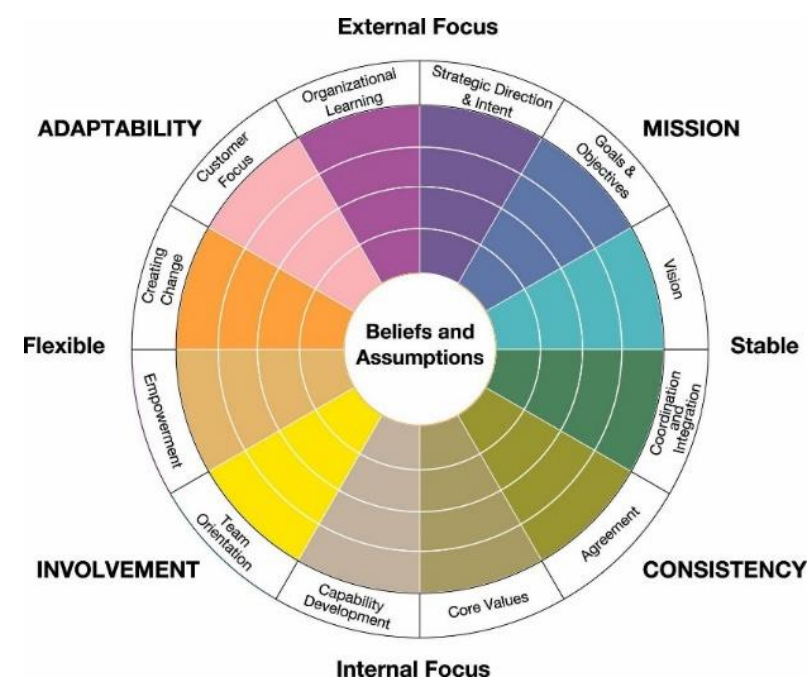

Fig. 1. Denison's model of organizational culture

A body of research on Denison's model found that effective organizations received high scores at all four features of organizational culture (involvement, adaptability, consistency and mission) (Vashghani Farhani, 2009). 


\section{CONCEPTUAL MODEL}

In the conceptual model presented in Figure 2, the effect of internal marketing has been tested on organizational silence mediated by organizational culture. Internal marketing was taken as the independent variable and was approached, in the present research, through Bansal's (2001) model. In this model, internal marketing is comprised of six dimensions: job security, extensive training, generous rewards, shared information, employee empowerment and reduced status distinction. Organizational silence, as the dependent variable, has got five dimensions, four of which (defensive, acquiescent, prosocial and opportunistic) were adopted from Knoll and van Dick (2012) and one (embarrassed) from Brinsfield (2013). Moreover, organizational culture was taken as the mediating variable in Denison's (2000) model. This variable was measured on four dimensions: involvement, consistency, adaptability and mission.

The conceptual model in the present research was developed out of several studies:

Esfahani et al. (2013) investigated the effect of internal marketing on organizational silence and found that, if parameters of the former are improved, employee satisfaction is improved too, followed by less silence in organization. Thus, organizational goals can be attained. In their research on the correlation of internal marketing and organizational culture, Fathollahi et al. (2016) found a significant positive correlation. Development of internal marketing was followed by the emergence of proper culture, communications and structures within the organization. In some other research, Safari et al. investigated the effect of organizational culture on organizational silence and concluded that organizations which enjoyed a richer and potent culture had employees more committed to organizational values and goals. Therefore, such committed employees kept much less frequently silent and instead tended to express their issues to the management. Thus, there exists a negative correlation between organizational culture and organizational silence, as an increase in the former is followed by a decrease in the latter. Taliban et al. (2015) investigated the mediating effect of organizational culture on internal marketing and employee satisfaction. Both theoretically and practically, this research revealed that creating a richer organizational culture can improve internal marketing and employee satisfaction with work, which in its own turn, is followed by less silence.

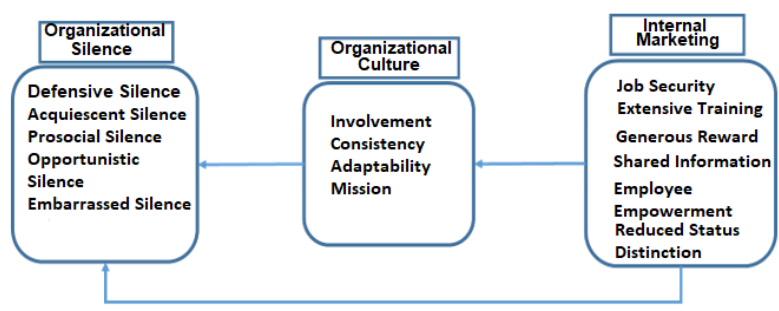

Fig. 2. Proposed model in the present research

\section{RESEARCH HYPOTHESES}

The hypotheses tested in the present research are:

H1: Internal marketing has a statistically significant negative effect on organizational silence of Ferdowsi University employees.

H2: Internal marketing has a statistically significant positive effect on organizational culture of Ferdowsi University employees.

H3: Organizational culture has a statistically significant negative effect on organizational silence of Ferdowsi University employees.

H4: Organizational culture mediates the effect of internal marketing on organizational silence of Ferdowsi University employees.

\section{METHODOLOGY}

The present applied research was a descriptive survey. The target population was all employees of Ferdowsi University of Mashhad in 2018 which was estimated at 968 in total. The sampling method was convenient which led to the selection of 275 employees. Three Questionnaires were used to collect the required data: Internal Marketing questionnaire (Pournabi, 2015) comprised of 30 items, Organizational Silence (Mirkamali et al., 2017) with 25 items and Organizational Culture (Denison, 2000) with 36 items. All items were to be rated on a 5-level Likert scale ranging from totally disagree to totally agree (1-5). For statistical analysis, SPSS and smartPLS were used.

\section{FINDINGS}

The descriptive information of the sample is summarized in Table 1.

Table I. Demographic Information of the Research Sample

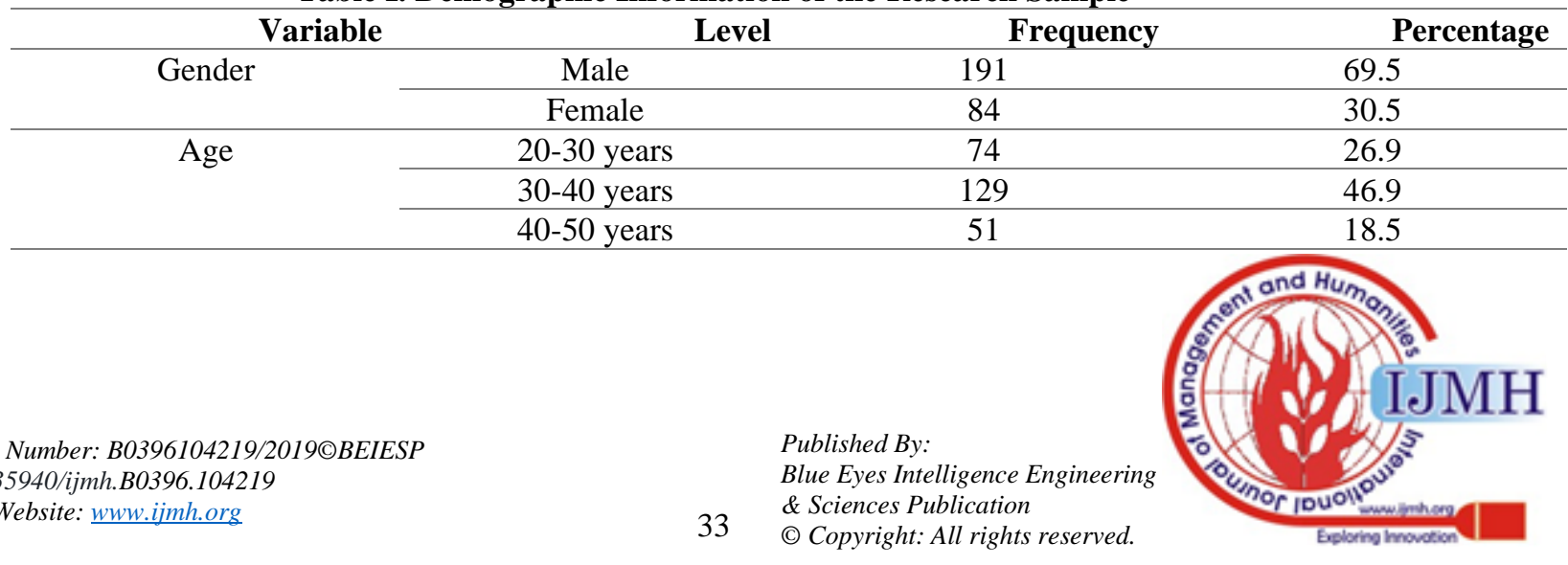




\begin{tabular}{|c|c|c|c|}
\hline & $50<$ & 21 & 7.6 \\
\hline \multirow[t]{5}{*}{ Education } & Diploma & 42 & 15.3 \\
\hline & Associate Degree & 15 & 5.5 \\
\hline & B.A./B.S. & 143 & 52 \\
\hline & M.A./M.S. & 70 & 25.5 \\
\hline & Ph.D. & 5 & 1.8 \\
\hline \multirow[t]{7}{*}{ Work Experience } & 5 years $>$ & 7 & 2.5 \\
\hline & $5-10$ years & 38 & 13.8 \\
\hline & 11-15 years & 110 & 40 \\
\hline & 16-20 years & 23 & 8.4 \\
\hline & 21-25 years & 25 & 9.1 \\
\hline & 26-30 years & 68 & 24.7 \\
\hline & 30 years $<$ & 4 & 1.5 \\
\hline \multirow[t]{4}{*}{ Employment Type } & Daily-paid & 122 & 44.4 \\
\hline & Contractual (short-term) & 106 & 38.5 \\
\hline & Contractual (Long-term) & 29 & 10.5 \\
\hline & Permanent & 18 & 6.5 \\
\hline
\end{tabular}

\section{A. Test Reliability estimates}

As presented in Table 2, to check the reliability of the tests used in this research, Cronbach's alpha test of internal consistency was used along with PLS approach, as the main statistical analysis was done in SEM. The cutoff point was taken as .7. Values exceeding this point were taken as acceptable.

Table II. Reliability Test Results of the Scales and Sub-scales

\begin{tabular}{lll}
\hline Scale/Sub-scale & Cronbach's alpha & PLS \\
\hline INTERNAL MARKETING & .971 & .943 \\
\hline Extensive training & .935 & .951 \\
\hline Generous reward & .881 & .914 \\
\hline Job security & .903 & .928 \\
\hline Shared information & .926 & .944 \\
\hline Empowerment & .910 & .933 \\
\hline Reduced status distinction & .931 & .948 \\
\hline ORGANIZATIONAL SILENCE & .940 & .918 \\
\hline Defensive silence & .773 & .847 \\
\hline Acquiescent silence & .905 & .926 \\
\hline Prosocial silence & .829 & .886 \\
\hline Opportunistic silence & .749 & .857 \\
\hline Embarrassed silence & .827 & .882 \\
\hline ORGANIZATIONAL CULTURE & .952 & .898 \\
\hline Involvement & .859 & .889 \\
\hline Consistency & .893 & .914 \\
\hline Adaptability & .886 & .910 \\
\hline Mission & .935 & .946 \\
\hline
\end{tabular}

\section{B. Test Validity}

As indicated in Table 3, Average Variance Extracted (AVE) was used to check the convergent validity of the tests Values at or above .5 were taken as acceptable according to Fornell and Larcker (1981).

Table III. Convergent Validity of Research of the Scales and Sub-scales

\begin{tabular}{lll}
\hline Scale & Sub-scale & AVE \\
\cline { 2 - 3 } Internal Marketing & Extensive training & .795 \\
\cline { 2 - 3 } & Generous reward & .682 \\
\cline { 2 - 3 } & Job security & .721 \\
\cline { 2 - 3 } & Shared information & .772 \\
\cline { 2 - 3 } & Empowerment & .738 \\
\cline { 2 - 3 } Organizational Silence & Reduced status distinction & .784 \\
\hline
\end{tabular}


Effect of Internal Marketing on Organizational Silence Mediated by Organizational Culture: the Case of Ferdowsi University Employees

\begin{tabular}{lll}
\hline & Acquiescent silence & .641 \\
\cline { 2 - 3 } & Prosocial silence & .660 \\
\cline { 2 - 3 } & Opportunistic silence & .667 \\
\cline { 2 - 3 } & Embarrassed silence & .612 \\
\hline \multirow{2}{*}{ Organizational Culture } & Involvement & .573 \\
\cline { 2 - 3 } & Consistency & .545 \\
\cline { 2 - 3 } & Adaptability & .542 \\
\cline { 2 - 3 } & Mission & .660 \\
\hline
\end{tabular}

Discriminant validity of a test shows that the correlation of a factor and its indicators exceed the correlation of cross-loadings. According to Fornell and Larcker (1981), the AVE of each of the latent construct should be higher than the highest squared correlation with any other latent variable. If that is the case, discriminant validity is established on the construct level. An observation of Tables 4 and 5 shows that the latter resembles the former except for that the main diagonal of this matrix is made up of squared AVE values. In Table 4 , the values in the main matrix diagonal are 1 . Thus, as Fornell and Larcker's (1981) matrix of discriminant validity shows in Table 4, the only difference lies in the main diameter.

Table IV. Correlation Matrix of the Scales

\begin{tabular}{llll}
\hline Scale & Internal Marketing & Organizational Silence & Organizational Culture \\
\hline Internal Marketing & 1.000 & & \\
\hline Organizational Silence & -.766 & 1.000 & 1.000 \\
\hline Organizational Culture & .486 & -.609 & \\
\hline
\end{tabular}

Table V. Correlation Matrix of the Scales (Fornell \& Larcker)

\begin{tabular}{llll}
\hline Scale & Internal Marketing & Organizational Silence & Organizational Culture \\
\hline Internal Marketing & .857 & & \\
\hline Organizational Silence & -.766 & .835 & .830 \\
\hline Organizational Culture & .486 & -.609 & \\
\hline
\end{tabular}

Table 6 includes a summary of the criteria of predictive accuracy. One criterion was the coefficient of determination $\left(\mathrm{R}^{2}\right.$ or $\left.\mathrm{r}^{2}\right)$ which is the proportion of variance in dependent variable that is predictable from the independent variable. According to Fornell and Larcker (1981), the acceptable range of $\mathrm{R}^{2}$ in SEM is .1-.87. The higher the $\mathrm{R}^{2}$ value, the higher the prediction power of the independent variable concerning the dependent variable. The $\mathrm{R}^{2}$ values were estimated and reported in Table 6 and, as it can be observed, they are all significant which points to a high prediction power.

The next criterion of predictive relevance was $Q^{2}$ value, introduced by Stone and Geisser (1975). Table 6 displays $\mathrm{Q}^{2}$ values estimated for the present research variables. If the $\mathrm{Q}^{2}$ value reaches $.02, .15$ and .32 respectively, the prediction power is interpreted as low, moderate and high. Accordingly, this value is high for all the variables addressed in the present research.

Table VI. R2 and Q2 Estimates for the Scales and Sub-Scales

\begin{tabular}{llll}
\hline Scale & Sub-scale & $\mathbf{R}^{2}$ & $\mathbf{Q}^{\mathbf{2}}$ \\
\hline \multirow{4}{*}{ Internal Marketing } & Extensive training & .705 & .556 \\
\cline { 2 - 4 } & Generous reward & .612 & .388 \\
\cline { 2 - 4 } & Job security & .800 & .573 \\
\cline { 2 - 4 } & Shared information & .835 & .641 \\
\cline { 2 - 4 } & Empowerment & .718 & .527 \\
\cline { 2 - 4 } Organizational Silence & Reduced status distinction & .740 & .577 \\
\cline { 2 - 4 } & Defensive Silence & .574 & .271 \\
\cline { 2 - 4 } & Acquiescent silence & .843 & .538 \\
\cline { 2 - 4 } & Prosocial silence & .389 & .252 \\
\cline { 2 - 4 } & Opportunistic silence & .869 & .566 \\
\cline { 2 - 4 } & Embarrassed silence & .809 & .486 \\
\hline \multirow{2}{*}{ Organizational Culture } & Involvement & .618 & .274 \\
\cline { 2 - 4 } & Consistency & .806 & .437 \\
\cline { 2 - 3 } & Adaptability & .575 & .302 \\
\cline { 2 - 3 } & Mission & .757 & \\
\hline
\end{tabular}

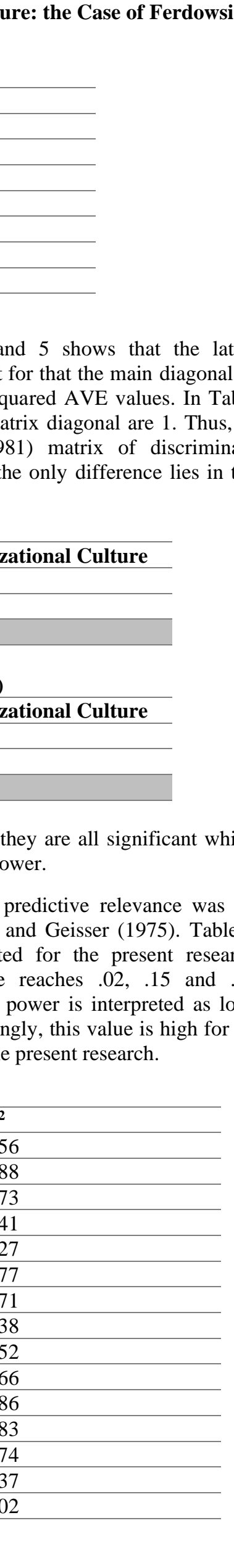




\section{SEM Results}

Figure 3 shows the analysis of the structural model proposed in this research. For the analysis of this model, there is no need for research questions. The main scales of the research are analyzed.

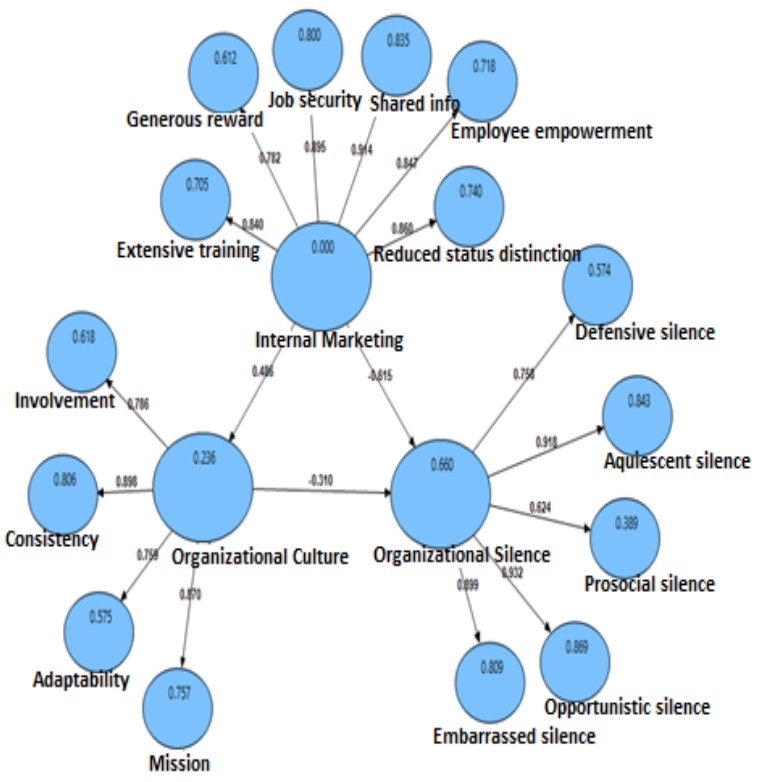

Figure 3. Standardized estimates of the default model

\section{T-values in SEM}

To check the correlation of factors within a model, tvalues are the basic estimates. If they exceed 1.96, the correlation is confirmed and the research hypothesis is accepted at a confidence interval of .95. As indicated in Figure 4, t-values exceed 1.96. Thus, the correlation among all research variables is significant $(\mathrm{t}>1.96)$

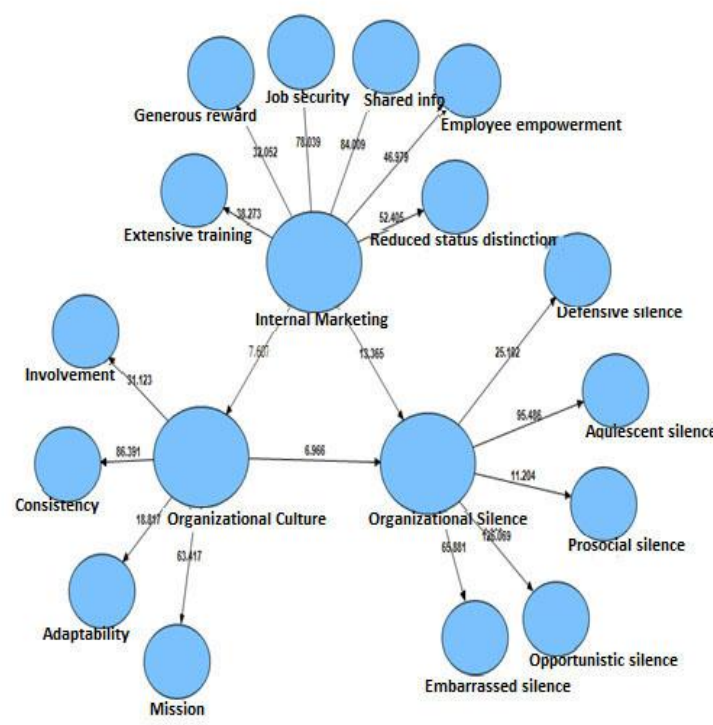

Fig. 4. Estimated t-values in the default model

Table VII. Factor Loadings and T-Values of the Scales and Sub-Scales

\begin{tabular}{llll}
\hline Scale & Sub-scale & Factor loading & t-value \\
\hline Internal Marketing & Extensive training & .840 & 38.273 \\
\cline { 2 - 4 } & Generous reward & .782 & 32.052 \\
\cline { 2 - 4 } & Job security & .895 & 78.039 \\
\cline { 2 - 4 } & Shared information & .914 & 84.009 \\
\cline { 2 - 4 } & Empowerment & .847 & 46.979 \\
\cline { 2 - 4 } & Reduced status distinction & .860 & 52.405 \\
\hline Organizational Silence & Defensive Silence & .758 & 13.365 \\
\cline { 2 - 4 } & Acquiescent silence & .918 & 7.607 \\
\cline { 2 - 4 } & Prosocial silence & .624 & 25.102 \\
\cline { 2 - 4 } & Opportunistic silence & .932 & 95.486 \\
\cline { 2 - 4 } & Embarrassed silence & .899 & 11.204 \\
\hline Organizational Culture & Involvement & .786 & 65.881 \\
\cline { 2 - 4 } & Consistency & .898 & 6.966 \\
\cline { 2 - 4 } & Adaptability & .759 & 31.123 \\
\cline { 2 - 4 } & Mission & .870 & \\
\hline
\end{tabular}

As indicated in Table 7, the correlation among all factors is statistically significant, as the t-values exceed 1.96. Accordingly, the research hypotheses are tested.

\section{Hypothesis Testing}

H1: Internal marketing has a statistically significant negative effect on organizational silence of Ferdowsi University employees.

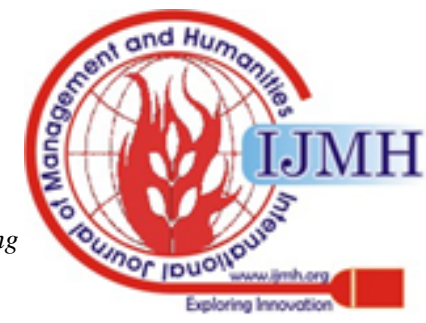


Effect of Internal Marketing on Organizational Silence Mediated by Organizational Culture: the Case of Ferdowsi University Employees

Table VIII. Testing the First Research Hypothesis

\begin{tabular}{lllll}
\hline $\begin{array}{l}\text { Dependent } \\
\text { Variable }\end{array}$ & $\begin{array}{l}\text { Independent } \\
\text { Variable }\end{array}$ & $\begin{array}{l}\text { Standardized } \\
\text { Estimate }\end{array}$ & T-value & Result \\
\hline $\begin{array}{l}\text { Organizational } \\
\text { Silence }\end{array}$ & Internal Marketing & -.615 & 13.365 & Accepted \\
\hline
\end{tabular}

As it can be observed in Table 8, the path coefficient of internal marketing and organizational silence was negative (-.615) and the t-value exceeded 1.96. Thus, it can be concluded that internal marketing negatively and significantly affected the organizational silence of employees in Ferdowsi University of Mashhad. Thus, the first research hypothesis can be accepted.

H2: Internal marketing has a statistically significant positive effect on organizational culture of Ferdowsi University employees.

Table IX. Testing the Second Research Hypothesis

\begin{tabular}{lllll}
$\begin{array}{l}\text { Dependent } \\
\text { Variable }\end{array}$ & $\begin{array}{l}\text { Independent } \\
\text { Variable }\end{array}$ & $\begin{array}{l}\text { Standardized } \\
\text { Estimate }\end{array}$ & T-value & Result \\
\hline $\begin{array}{l}\text { Organizational } \\
\text { Culture }\end{array}$ & Internal Marketing & .486 & 7.607 & Accepted \\
\hline
\end{tabular}

As indicated in Table 9, the path coefficient of internal marketing and organizational culture was positive (.486). Tvalue was estimated at 7.607 . As this value exceeds 1.96 , it can be concluded that internal marketing affects organizational culture of employees at Ferdowsi University of Mashhad in a significant and positive way. Thus, the second research hypothesis can be accepted.

H3: Organizational culture has a statistically significant negative effect on organizational silence of Ferdowsi University employees.

Table X. Testing the Third Research Hypothesis

\begin{tabular}{lllll}
\hline $\begin{array}{l}\text { Dependent } \\
\text { Variable }\end{array}$ & $\begin{array}{l}\text { Independent } \\
\text { Variable }\end{array}$ & $\begin{array}{l}\text { Standardized } \\
\text { Estimate }\end{array}$ & T-value & Result \\
\hline $\begin{array}{l}\text { Organizational } \\
\text { Silence }\end{array}$ & $\begin{array}{l}\text { Organizational } \\
\text { Culture }\end{array}$ & -.310 & 6.966 & Accepted \\
\hline
\end{tabular}

As it can be concluded from Table 10, the path coefficient of organizational culture and organizational silence was negative (-.310). The t-value was estimated at 6.966 which exceeds 1.96 and shows that organizational culture significantly and negatively affects organizational silence among the employees of Ferdowsi University of Mashhad. Therefore, the third research hypothesis can be accepted.

H4: Organizational culture mediates the effect of internal marketing on organizational silence of Ferdowsi University employees.

In statistics, the Sobel test is a method of testing the significance of a mediation effect. In this test, $\mathrm{z}$-value is estimated through the following formula, and if this value exceeds 1.96, the significance of an effect is confirmed at CI-95\%.

$$
Z-\text { value }=\frac{0.486 \times(0.310)}{\sqrt{\left(0.486^{2} \times 0.045^{2}\right)+\left(0.310^{2} \times 0.064^{2}\right)+\left(0.045^{2} \times 0.064^{2}\right)}}=\frac{0.151}{0.030}=5.078
$$

Table XI. Testing the Fourth Research Hypothesis

\begin{tabular}{lllll}
\multicolumn{4}{c}{ Table XI. Testing the Fourth Research Hypothesis } \\
\hline $\begin{array}{l}\text { Dependent } \\
\text { Variable }\end{array}$ & $\begin{array}{l}\text { Independent } \\
\text { Variable }\end{array}$ & $\begin{array}{l}\text { Standardized } \\
\text { Estimate }\end{array}$ & T-value & Result \\
\hline $\begin{array}{l}\text { Organizational } \\
\text { Silence }\end{array}$ & Internal Marketing & .151 & 5.078 & Accepted \\
\hline
\end{tabular}

$$
\mathrm{Z}-\text { value }=\frac{|\mathrm{a} \times \mathrm{b}|}{\sqrt{\left(\mathrm{b}^{2} \times \mathrm{S}_{\mathrm{a}}^{2}\right)+\left(\mathrm{a}^{2} \times \mathrm{S}_{\mathrm{b}}^{2}\right)+\left(\mathrm{S}_{\mathrm{a}}^{2} \times \mathrm{S}_{\mathrm{b}}^{2}\right)}}
$$

In this formula:

a: path coefficient of independent and mediating variables b: path coefficient of mediator and dependent variable

Sa: standard error of the path between independent Sb: standard error of the path between dependent variable and mediator 
According to Table 11, the coefficient of the indirect path between internal marketing and organizational silence was .151, and the t-value was estimated at 5.078. As the tvalue exceeds 1.96, it can be concluded that organizational culture mediates the effect of internal marketing on organizational silence among the employees of Ferdowsi University of Mashhad. Thus, the fourth research hypothesis is accepted.

\section{DISCUSSIONS AND CONCLUSIONS}

The first research hypothesis dealt with the effect of internal marketing on organizational silence in Ferdowsi University of Mashhad. Hypothesis testing revealed that internal marketing significantly and negatively affected organizational silence.

This finding is consistent with the findings of Ahmadifard (2016), Baqeri (2017) and Nasr Isfahani et al. (2013). Internal marketing in Ferdowsi University points to the fact that managers should take the staff as customers and take them as seriously as the external customers (students). Managers should value their staff and thus influence members' attitude and behavior. They can help them express ideas freely and break organizational silence. It can, thus, be concluded that improving internal marketing can reduce organizational silence among the staff of Ferdowsi University of Mashhad.

The second research hypothesis explored the effect of internal marketing on organizational culture. As the results showed the significant positive effect of the former on the latter, this hypothesis was accepted. This finding is consistent with the work of research by Fathollahi (2017).

Internal marketing is an internal outlook to an organization and is of an utmost importance in the development of an organization. To know an organization of affiliation well and evaluate the behavior and performance of members, it is essential to be aware of organizational culture. A myriad of factors affect organizational culture. Internal marketing, if implemented effectively, can tremendously change an organization. Any change within an organization is closely associated with the culture of that organization. The present findings showed that internal marketing significantly and positively affect internal marketing.

The third research hypothesis explored the effect of organizational culture on organizational silence which showed a significant negative effect of internal marketing on organizational culture. This finding is in line with the reports by Rajabi Farjad (2018), Safari (2017), Aqayi (2017), Goudarzi (2015) and Khamesi Hamaneh (2013). Organizational silence is defined as the staff's reluctance to express their behavioral, cognitive and effective evaluation of organizational posts. Silence is a function of several features including the decision-making process and the process involved in managing the staff's culture and perceptions. If silence dominates, it can demotivate the staff to participate in decision-making. A key factor influencing organizational silence is organizational culture. Managerial issues including the dominant culture can be a main issue in organizational silence. If managers create trust, they can seize communicative chances tom break organizational silence. Staff would not only avoid keeping silence on organizational issues, but they also feel responsible toward the values and goals of the whole organization and attempt to cooperatively think of solutions to organizational problems. It can thus be concluded that a potent organizational culture can significantly and negatively affect organizational silence.

The fourth research hypothesis explored the moderating role of organizational culture between internal marketing and organizational silence. There is a dearth of research into this aspect. Thus, the present research aimed to fill the gap and see if organizational culture moderated the effect of internal marketing on the organizational silence of those affiliated with Ferdowsi University of Mashhad. As there is yet no research conducted with this respect, this hypothesis cannot be compared with any related research. However, Taliban (2015) investigated the moderating role of organizational culture on the staff satisfaction. This research showed that one variable that can be employed to increase the effect of internal marketing on employee satisfaction was organizational culture.

The present research revealed that improving internal marketing can better develop organizational culture in the staff of Ferdowsi University of Mashhad.

\section{IMPLICATIONS}

As the present results showed, internal marketing and organizational silence were negatively correlated. In other words, an increase in the internal marketing of the target organization is followed by a decrease in employees' organizational silence. In this research, the mediating role of organizational culture was also explored and the results revealed that an increase in internal marketing is followed by higher organizational culture which, in turn, leads to less silence on the part of employees. In the light of the present findings, there are a number of practical implications for enhanced internal marketing in Ferdowsi University of Mashhad.

Job security: Managers are recommended to create a sense of job security among employees which can be facilitated through the provision of required training, clarification of employment rules and regulations, positive and negative reinforcement especially as a pay rise, promotion and so on and ensuring them of the essentiality of their role and expertise. Employees are to be encouraged to express their personal commentaries and be ensured that their expression of ideas does not lead to their dismissal. People obsessed with the fear of losing jobs cannot be expected to comment on organizational issues freely.

Extensive diverse training: Extensive training is needed in an organization to convey and enculturate the required content to employees. Training courses and seminars can be held to promote internal marketing in an academic environment and develop the necessary culture within the organization to break employees' silence.

Generous rewards: Managers are supposed to reward employees financially or else to create a sense of commitment. When one feels committed to one's job, $\mathrm{s} /$ he strives to make progress and tends to express ideas and put forth solutions to help solve the existing issues. The rewards need to be consistent with employees' interests and needs.

Blue Eyes Intelligence Engineering

\& Sciences Publication

(C) Copyright: All rights reserved.

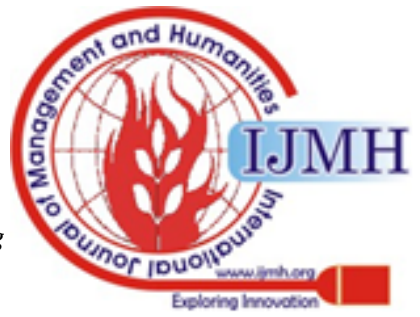


Shared information: Information should be clearly and unlimitedly shared with all employees of the organization so that everybody is informed of all affairs within the workplace. This would facilitate communications between superior and inferior ranks, elucidate on the roles of employees and promote their positive performance and lower organizational silence.

Employee empowerment: Promoting competencies among employees can create self-confidence followed by courage and freedom of self-expression. Managers are expected to implement all these practically so that they gradually turn into an organizational culture. difference among salaries of those working at the same rank is reduced and so is the difference between different ranks in general, employees come to know that there is no such a thing as discrimination within the organization. To do so, employees' work is to be evaluated regularly and practically so that they feel their endeavors receive enough attention. Employees of the same rank doing the same load of work should have the same perks and benefits to make sure there is no discrimination meant.

\section{SUGGESTIONS FOR FURTHER RESEARCH}

The present research aimed to explore the effect of internal marketing on organizational silence mediated by organizational culture among the employees of Ferdowsi University of Mashhad. Thus, it is suggested that the present model is applied to other universities of Iran. Moreover, the present research population was comprised of university employees, which can become larger to include, for example, faculty members too. For data collection, other instruments can be also used besides questionnaires such as interview, observation and so on. Finally, it can be suggested to analyze the target variables in other ways. The dependent, independent and mediating variables could be replaced such other factors as organizational performance, organizational voice, willingness to quit work and so on.

\section{REFERENCES}

1. Aqayi, M. \& Aqayi, R. (2014). Proposing a conceptual model of organizational agility. Technology Development Quarterly, 39(10). 37-43.

2. Baker, K.A. (2002). Organizational culture. Rerieved September, 2009 from http://www.au.af.mil/au/awc/awcgate/doe/benchmark/11

3. Bansal, H., \& Morris, B. (2001). The impact of internal marketing activites on external marketing outcomes. Journal of Quality Management, 6(1), 61-76.

4. Baqeri, G., Shahir-Tofiq, A., Zarifi, M., \& Deldar, E. (2017). Correlation of internal marketing and organizational silence in Youngsters' Sports Headquarters. Applied Research in Management, 5(20), 61-70.

5. Baqeri, G., Zarei, R. \& Nikayin M. (2010). Organizational silence: basic concepts and development. Ideal management Model, 1(4). 5563.

6. Brinsfield, C. T. (2013). Employee silence motives: Investigation of dimensionality and development of measures. Journal of Organizational Behavior, 34(5), 671-697.

7. Dalvi, M., \& Sefiddashti, F. (2013). The Effect of Internal Marketing on Organizational Silence: Case Study in Esfahan Taxation Office. Journal of Management and Development Process, 26(1), 139-160.

8. Danayifard, H., \& Panahi, B. (2011). Analysis of employees' occupational attitudes in state organizations and explanation of organizational silence and organizational silence behavior. Journal of Revolution Management, 3(2).
Reduced status distinction among employees: If the Organizational

9. Denison, D. R. (2000). Organizational culture: Can it be a key lever for driving organizational change? In S. Carwright \& C. Cooper (Eds.), The handbook of organizational culture. London: John wiley \& Sons.

10. Doostmohammadi, M. (2007). Correlation of organizational culture and employee performance in radio station: employees' perspective. (M.A.), TV/Radio Faculty,

11. Dyne, L. V. (2003). Conceptualizing employee silence and employee voice as multidimensional constructs. Journal Of Management Studies, 40(6), 1359-1392.

12. Fathollahi, M., Kord-Jamshidi, M., Darabi, S., \& Shirkhani, S. (2016). Exploring the effect of organizational culture on internal marketing: the case of gas company in Ilam. Paper presented at the International Conference of Management and Resisting Economy. https://www.civilica.com/Paper-CMRE01-CMRE01_014.html

13. Fornell, C. \& Larcker, D. F. (1981). Evaluating structure structural equation models with unobservable variables and measurement error. Journal of Marketing Research, 18(1), 39-50.

14. Geisser, S. (1975). The predictive sample reuse method with applications. Journal of the American Statistical Association, 70(350), 320-328.

15. Gounaris, S. (2008). The notion of internal market orientation and employee job satisfaction: Some preliminary evidence. Journal of Services Marketing, 22(1), 68-90.

16. Gronross, C. (2000). Service management and marketing: A customer relationship management approach. New Jersey: John Wiley.

17. Henriksen, K., \& Dayton, E. (2006). Organizational silence and hidden threats to patient safety. Health services research, 41(4), 15391554.

18. Imani, S., Gasgari, R. \& Gheitani, A. (2015). Effect of internal marketing on employee performance mediated by organizational innovation in office affiliates of Aqajari Gasoil company. Commercial Management Scientific Journal, 7(2). 315-338.

19. Karami, M., Mirkamali, M., \& Pourkarimi, J. (2016). Analyzing organizational silence and its dimensions: the case of Tehran University employees Journal of Educational Management Research, 7(28), 67-94.

20. Khamesihamaneh, M. (2013). Exploring the effect of organizational culture on organizational silence mediated by perceived organizational equity: the case of Yazd University. (M.A.), Islamic Azad University of Semnan, Semnan.

21. Knoll, M., \& van Dick, R. (2013). Do I Hear the Whistle...? A First Attempt to Measure Four Forms of Employee Silence and Their Correlates. Journal of Business Ethics, 113(2), 349-362. doi:10.1007/s10551-012-1308-4

22. Mirkamali, S. M., Poorkarimi, J., \& Karami, M. (2017). A study of mediating role of organizational justice in the relationship between university managers' ethical leadership style and employees' organizational silence. Quarterly Journal of Research and Planning in Higher Education, 23(1), 1-25.

23. Monavarian, A., \& Bakhtaei, A. (2006). Recognition of organizational culture in the light of Denson's model" the case of industrial management organization. Paper presented at the The 4th International Management Conference. https://www.civilica.com/Paper-IRIMC04-IRIMC04_078.html

24. Morrison, E., \& Milliken, F. (2000). Organizational silence: A barrier to change and development in pluralistic world. Academy of Management Review, 25(4), 706-725.

25. Park, J., \& Kim, T. (2009). Do types of organizational culture matter in nurse job satisfaction and turnover intention? . Leadership in Health Services, 22(1), 20-38.

26. Perlow, L. \& Williams, S. (2003). Is silence killing your company?, Harvard Business Review, May, 3-4

27. Pezeshknia, S.A. \& Yaqubi, N.M. (2016). Effective relationships and organizational silence: the case of urban water and wastewater in Southern Khorasan. Shabak Monthly, 2(3). 29-42.

28. Piercy, N. \& Morgan, N. (1991). Internal marketing: the missing half of the marketing program, Long Range Planning, 24(2). 82-93

29. Pinder, C., \& Harlos, H. (2001). Employee silence: Quiescence and acquiescence as responses to perceived injustice. Research in Personnel and Human Resource Management, 20, 331-369.

30. Rafiq, M., \& Ahmed, P. R. (1993). Scope of internal marketing: Defining the boundary between marketing and human resources management. Journal of Marketing Management, 9(3), 219-232. 
31. Taliban, Z., Haji-Mohammadi, P. S., \& Taliban, F. (2015). Exploring the mediating role of organizational culture on internal marketing ans employee satisfaction. Paper presented at the International Conference of Management and Social Sciences, Dubai. https://www.civilica.com/Paper-ICMSCONF01-

ICMSCONF01_130.htm

32. Unesifar, M., Mohaqar, A., \& Unesifar, A. (2013). Effect of internal marketing parameters on improved employee performance: the case of Shahid Sadoughi Hospital in Yazd. Healthcare Management Journal, 2(3), 19-28.

33. Vashghani Farhani, S. (2009). Correlation of organizational culture and customer satisfaction in Sepah Bank. (M.A.), Tarbiat Modares University.

\section{AUTHORS PROFILE}

Raoufeh Sadat Ja'farian is an M.A. candidate of Commercial Management field (subfield: Marketing). She is affiliated with Attar Institute of Higher Education in Mashhad, Iran.

Vajiheh Hoshyar holds a Ph.D. of Human Resource Management and is currently an assistant professor at Attar Institute of Higher Education.

Elham Yazdanmehr holds a Ph.D. of Applied Linguistics and is currently an assistant professor at Attar Institute of Higher Education.

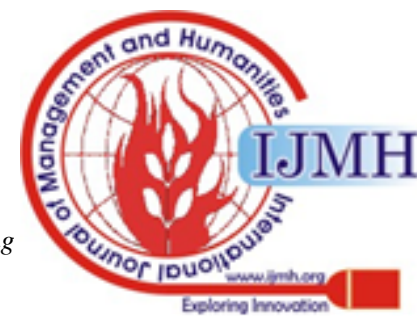

